\title{
The Disappearance of Style in the US Equity Market
}

Soosung Hwang and Stephen Satchell 


\title{
The Disappearance of Style in the US Equity Market
}

10 April 2000

\author{
Soosung Hwang \\ Department of Banking and Finance \\ City University Business School \\ City University
}

and

Stephen E. Satchell

Faculty of Economics and Politics and Trinity College

University of Cambridge

\footnotetext{
* Address correspondence to Stephen E. Satchell, Faculty of Economics and Politics, University of Cambridge, Austin Robinson Building, Sidgwick Avenue, Cambridge CB3 9DD, UK (Tel: 441223 335281, Fax: 441223 335475, Email: ses11@econ.cam.ac.uk). We would like to thank J. MacQueen and E. Fisher for helpful comments and Alpha Strategies Ltd. for financial support.
} 


\title{
The Disappearance of Style in the US Equity Market
}

\begin{abstract}
This paper investigates the modelling of style returns in the US and the returns to style "tilts" based on forecasts of enhanced future style returns. We use hidden Markov model to build our forecasts. Our finding that style returns are less forecastible in more recent years is consistent with the hypothesis that style returns are the result of anomalies rather than risk premia. The erosion of anomalous returns as public awareness of their presence is translated into strategies that arbitrage away the excess returns seems to be a hypothesis consistent with our modelling results.

Key Words: $\quad$ Factor Mimicking Portfolio, Markov Regime Switching Model,
\end{abstract} Trading rule, Style Indices, Anomalies.

JEL Classification: G11 


\section{Introduction}

The notion of equity style, introduced in the literature to practitioners by Sharpe (1992) and to academics by Fama and French (1992), has been very widely accepted in the US investment community. Since then, there have been many subsequent publications, see Kuberek (1998), Rozeff and Zaman (1998), Jensen, Johnson, and Mercer (1998), Bauman and Miller (1997), La-Porta (1996), and Siegel (1995) among others.

It is not clear that style returns have the same distribution through time. The determinants of the distribution of style returns are complex and unknown. They may be due to factors such as the tax regime, the regulatory framework for bankruptcy, sociodemographic factors and macro-economic factors. See Erb, Harvey, and Viskanta (1996. 1997), Ferson and Harvey (1997), Bauman, Conover, and Miller (1999) for example.

Furthermore, the creation of style indices and the adherence to style taxonomies by US managers may have arbitraged away many of the "anomaly" profits associated with the style. The difficulty in separating a risk factor from an anomaly has been the subject of work by Ferson, Sarkissian and Simin (1998). Some of the style returns may be available prior to their broader recognition but disappear once investors act upon the knowledge of the presence of such returns. We shall investigate this question statistically by seeing if our models exhibit parameter constancy through time and by computing returns to strategies based on our models.

State-of-the art models for equity returns try to capture the feature that exposures to particular risks changes with time. Furthermore the statistical properties of the risk factors may also exhibit separate changes. Although these changes can be modelled through a linear factor model framework, it is certainly of interest to model the stochastic processes for the risk factor returns using (simple) non-linear processes. 
This paper carries out such an exercise on US equity data. Previous unpublished research by Satchell and Yoon (1996) had found promising results for UK data from 1980 to 1995 when applying regime-switching Markov models to UK monthly equity data for the UK component of the MSCI global equity universe.

The purpose of this paper is to analyse whether there are regime shifts in stylebased returns for US equity. The data used consist of the US component of MSCI World Universe and the S\&P500/BARRA value and growth indices. In addition to analysing whether there are shifts in regime, we analyse if it is possible to earn excess returns by trading on this information. This exercise takes as given the existence of regime shifts.

Our research suggests that it is not possible to make excess returns from the style-based returns any more. Note that this conclusion rests on assumptions of the appropriateness of both the Markov regime-switching model and the trading rules used in this study. However, other simple statistics reported in this study support that there was a change in style factor returns around 1994. Considering the timing of the researches of Sharpe (1992) and Fama and French (1992) and the US financial industry's extensive exploitation of the styles since then, we conjecture that the excess return to style has been traded away due to both increased awareness and portfolio structuring along style lines. Of course, it may also be time-varying risk premia but without a clear model of the risk premia it is not possible to identify which is the case.

This paper is organised as follows. In Section 2 we consider definitions of factor mimicking portfolios and their methods of construction. In Section 3 we discuss Markov-Switching models. In Section 4 we present some empirical results for MSCI based style indices and the S\&P500/BARRA style indices. In Section 5 we investigate how to construct trading rules based on our forecasts. Further potential applications are 
also discussed in Section 5 whilst results follow in Section 6. Three Appendices contain some mathematical details, details of the S\&P500/BARRA style index construction methodology and our choice of style variables.

\section{Factor Mimicking Portfolios and Linear Factor Models}

In linear factor models, we need to calculate or estimate either the factors themselves, or their equilibrium risk premia or a portfolio that mimics one or the other. We shall discuss the last of these three cases. Our decision to concentrate on building forecasting models for the factor mimicking portfolios is in line with the more sophisticated practitioner models that assume that returns $r_{i t}$ are generated by a linear factor model. This is the basis of factor based optimisation procedure sold by investment technologists such as Barra or Quantec.

For our purposes, a factor-mimicking portfolio is a portfolio of assets whose returns are designed to be highly correlated with the (unobservable) factor values. Portfolios constructed from eigenvectors in principal component analysis are examples of factor mimicking portfolios. Factor mimicking portfolios are a useful and increasingly common tool in building linear factor models. They often take the form of a hedge portfolio. In equilibrium, the expected return to a factor mimicking portfolio should be the corresponding factor premium.

Even in cases when the factor is directly observable or pre-specified, it is often convenient to use factor mimicking portfolios. For example, if a particular factor does not correspond to a set of traded positions, it may be hard to argue that a pricing theory applies to it, although (by construction) it would apply to a factor mimicking portfolio. 
For a more detailed discussion on the general theory of factor mimicking portfolios, see Huberman et al. (1987).

The returns to the factor-mimicking portfolios mimic the factor values in a certain sense (remember that the factor values themselves are usually not directly observable). The linkage between the factor values and the corresponding factor premiums arises from theories such as the Arbitrage Pricing Theory which essentially links, in a noarbitrage world, the exposure of the stocks to the factors, and the risk premiums associated with the factors to the overall risk premium of the asset.

Suppose stock returns $r_{i, t}$ can be modelled as :

$$
r_{i, t}=\alpha_{i}+\sum_{f=1}^{m} \beta_{i, f} \phi_{f, t}+\varepsilon_{i, t}
$$

where $\beta_{i, f}$ is some measure of the exposure of stock $i$ to factor $f, \phi_{f, t}$ is some measure of the value of factor $f$ at time $t$, and $\varepsilon_{i, t}$ is noise. For each factor $f$, we rank the universe by an attribute of $f$. For instance, $f$ might be the Return on Equity factor and we would rank the universe of stocks by their Return on Equity attribute data. We then form an equally weighted portfolio that is long the top $n$-tile ranked by the $f$ attribute, and short the bottom $n$-tile, ranked by the $f$ attribute. The resulting hedge portfolio is the factor mimicking portfolio of factor $f$. The order of the $n$-tile should typically be small. Thus, the use of quartiles $(n=4)$ or thirds $(n=3)$ is probably more appropriate than the use of, for example, deciles $(n=10)$, because of the greater diversification produced. In this particular model we have used thirds.

The above procedure can be seen as a natural way to make the factor mimicking portfolios approximately uncorrelated. If the true factors are uncorrelated, then sorting by the attributes and constructing long and short positions relative to factor 1, say, 
should give a portfolio with little to no systematic exposure to factor 2. Actually, the attributes themselves may be strongly correlated and we do not expect to get fully uncorrelated portfolios as a consequence. However, we believe that our procedure is preferable to using factor analysis or principal components since then we usually lose any understanding of what the factors signify.

We assume that equation (1) holds for the factor mimicking portfolios and allow our exposures to vary with time. Thus we have

$$
r_{i, t}=\alpha_{i, t}+\sum_{f=1}^{m} \beta_{i, f, t} \phi_{f, t}+w_{i, t}
$$

where $\beta_{i, f, t}$ is exposure of asset $i$ to factor $f$ at time $t, \phi_{f, t}$ is the "value" of factor $f$ at time $t, \alpha_{i, t}$ is alpha of asset $i$ at time $t$, and $w_{i, t}$ is noise of asset $i$ at time $t$.

The factors may be forecastible and if the exposures are known, together with the alphas, we can forecast returns. Thus our previous models described by equations (1) and (2) can be used in at least two applications; (a) to build timing strategies on styles (factors); this is what we did in this study, (b) to forecast factors in stock selection models. For the case of (b), we could use analysis based on this study. By forecasting $\phi_{f, t}$ we could build stock selection models that take into account regime shifts in style. To complete such an exercise we would also need to calculate $\beta_{i, f, t}$, such a procedure would involve extra equations than the ones presented in this paper.

We consider fourteen style attributes, which are listed in Appendix 1; dividend/price ratio (DP), earnings/price ratio (EP), net-sales/price ratio (SP), bookvalue/price ratio $(\mathrm{BP})$, cash-flow/price ratio $(\mathrm{CP})$, earnings/book-value ratio $(\mathrm{RE})$, totaldebt/book-value ratio (DE), two attributes for growth in book value (EG1 and EG2), logarithmic capital value (SZ), and four style attributes (VL1, VL2, GR, and VG) which 
are combinations of the above attributes. The reason we chose them and not some others

were based on a mix of (a) data vailability in the MSCI universe, and (b) frequency of use by practitioners, see for example Bauman, Conover, and Miller (1999). The factor mimicking portfolios obtained with the fourteen attributes are named with prefix $F$ to each attributes name; e.g., FDP is the factor mimicking portfolio for dividend/price ratio (DP), FEP is the factor mimicking portfolio for earnings/price ratio (EP), etc. The US equities included in the MSCI World universe are used; there are 387 US equities among a total of 1521 equities included in the MSCI World universe. In addition, equallyweighting 387 US equities gives us an estimate of the equally weighted market portfolio.

Table 1 reports some statistical properties of monthly factor mimicking portfolio returns, US 3 month treasury bill returns, and market returns. Statistical properties of the 14 factor mimicking portfolios differ markedly. For example, large negative or positive returns are found in some factor mimicking portfolios such as FSZ, FDP, and FRE. Noting that the factor mimicking portfolios are zero-investment portfolios, large negative or positive returns might be attributed to "free-lunches"/anomalies, or as returns available for the tolerance of the factor risk.

The standard deviation of returns is large for FDP and FVL1. But none of the standard deviations of factor mimicking portfolios is larger than that of market returns. Estimates of skewness and excess kurtosis show that most factor mimicking portfolio returns are not normally distributed.

\section{Markov Switching Models}

Markov Switching Models have been used extensively in macroeconometrics as a means of capturing the different patterns of expected growth in output, see, for example, 
Filardo (1994), Goodwin (1993), Hamilton (1989). There have been fewer applications in finance. The key feature of these models is that there is a Markovian state variable, $S_{t}$, which is unobservable. There are many similar models where $S_{t}$ may be wholly or partly observed.

In what follows, we shall illustrate our discussion by considering book to price (value) as our particular factor value. The remarks we make, however, will apply to all factors. Our latent variable, $S_{t}$, will take the value 1 when value does well, and 0 when it does not. If we knew that $S_{t}=1$ at time $t$ we would know that, on average, a value-tilted portfolio would have higher return; it may have higher or lower volatility.

If we assume there are two states of the world and that $S_{t}$ is Markovian timehomogeneous, and stationary then,

$$
\begin{aligned}
& \operatorname{prob}\left(S_{t}=1 / S_{t-1}=1\right)=p_{11} \\
& \operatorname{prob}\left(S_{t}=0 / S_{t-1}=0\right)=p_{00}
\end{aligned} .
$$

The previous assumptions define all we need to know to model the distribution of $S_{t}$. In particular,

$$
\begin{aligned}
& \operatorname{prob}\left(S_{t}=0 / S_{t-1}=1\right)=1-p_{11} \\
& \operatorname{prob}\left(S_{t}=1 / S_{t-1}=0\right)=1-p_{00} .
\end{aligned}
$$

The process $S_{t}$ has an autoregressive representation of degree 1 with coefficient $\left(p_{00}+p_{11}-1\right)$. Thus a quick measure of whether $S_{t}$ is independent of $S_{t-1}$ is to compute $\left(p_{00}+p_{11}-1\right)$.

The ergodic long-run probabilities of the process $S_{t}, \pi_{0}=\operatorname{prob}\left(S_{t}=0\right)$ and $\pi_{1}=$ $\operatorname{prob}\left(S_{t}=1\right)$ can be computed as

$$
\begin{aligned}
& \pi_{0}=\frac{1-p_{11}}{2-p_{00}-p_{11}} \text { and } \\
& \pi_{1}=1-\pi_{0}=\frac{1-p_{00}}{2-p_{00}-p_{11}}
\end{aligned}
$$


Another quantity of interest is the number of periods one would expect to stay in the current state, $f_{i}, i=0,1$. It is straightforward to show that

$$
f_{i}=\frac{1}{1-p_{i i}}, \quad i=0,1
$$

In this section our observable rate of return to a value portfolio, $r_{t}$, is combined with our latent state variable, $S_{t}$ as follows. Our proposed model is,

$$
r_{t}=\mu_{1} S_{t}+\left(1-S_{t}\right) \mu_{2}+\left(o_{1} S_{t}+o_{2}\left(1-S_{t}\right)\right)_{t}
$$

where $\varepsilon_{t} \sim N(0,1)$ and $\mu_{1}, \mu_{2}, \sigma_{1}, \sigma_{2}$ are parameters to be estimated, $\sigma_{1}, \sigma_{2}$ being positive. To capture further predictability that may be present in $r_{t}$, we extend the model by assuming that

$$
\varepsilon_{t}=\sum_{j=1}^{k} \rho_{j} \varepsilon_{t-j}+v_{t}
$$

where $\left(\rho_{l}, \ldots, \rho_{k}\right)$ are autoregressive parameters and $v_{t}$ is a white-noise process. In what follows, we shall initially estimate the models with (a) $\sigma_{l}=\sigma_{2}=\sigma$ (a common variance) and (b) $\sigma_{1} \neq \sigma_{2}$ (different variances). In this study, we assume that there are two regimes with four lags $(k=4)$. Then the above Markov switching model for observed returns are

$$
r_{t}-\mu_{s_{t}}=\rho_{1}\left(r_{t-1}-\mu_{s_{t-1}}\right)+\rho_{2}\left(r_{t-2}-\mu_{s_{t-2}}\right)+\rho_{3}\left(r_{t-3}-\mu_{s_{t-3}}\right)+\rho_{4}\left(r_{t-4}-\mu_{s_{t-4}}\right)+\sigma v_{t}
$$

here $\mu_{s_{t-\tau}}$ represents $\mu_{1}$ when $S_{t_{-}}=1$ and $\mu_{2}$ when $S_{t_{-}}=0$ for $\tau=0,1,2,3,4$.

We use the Gauss software package with the Maximum likelihood module throughout this study. The Gauss code originally distributed by J. Hamilton is modified for our calculations. Markov Switching models have many local maxima which give converged estimates. To find out the global maximum point, we need to try many initial value sets and compare the maximised values. As in Goodwin (1993), different initial 
values are only allowed for $\mu_{1}, p_{11}$, and $p_{00}$. We use 36 different initial value sets; the sets formed from $\mu_{1}, p_{11}$, and $p_{00}$ are $\mu_{1}=0.5,1,2,4, p_{11}=0.25,0.5,0.75$, and $p_{00}=0.25,0.5$, 0.75. Other parameters are set to zero except $\mu_{0}=-1$ and $\sigma_{l}$ and $\sigma_{2}$ are set to the sample standard deviation of the factor mimicking portfolio returns. A detailed explanation of the estimation and forecasting methods used is presented in Appendix 2.

\section{Empirical Results}

\subsection{Estimation Results}

Tables 2 and 3 report converged estimates for the assumption of constant variance $\left(\sigma_{l}=\right.$ $\sigma_{2}=\sigma$ ) and for different variance versions of our model as discussed in the previous section $\left(\sigma_{l} \neq \sigma_{2}\right)$. Due to convergence difficulties, only estimates for 8 factor mimicking portfolios (constant variance) and 9 factor mimicking portfolios (different variances) are reported. Most convergence errors occur when either $\mathrm{p}_{11}$ or $\mathrm{p}_{00}$ hits the restriction (zero and one), which are frequently found during the estimation of Markov regime switching models.

We shall discuss in detail two cases, book value/price $\mathrm{FBP}_{1}$, and $\mathrm{FBP}_{2}$. The subscripts ' 1 ' and ' 2 ' refer to whether the variance is constant across regimes or not.

The estimated model for $\mathrm{FBP}_{1}$, when $\sigma_{1}=\sigma_{2}=\sigma$, is

$$
r_{t}=4.433 S_{t}+(-0.454)\left(1-S_{t}\right)+1.996 \varepsilon_{t}
$$

and all lagged coefficients are insignificant. These estimates imply that the expected return to value is $4.43 \%$ per month that value outperforms. If value underperforms, its opposite (growth, state 0 ) has a return of $0.454 \%$ per month. The transition probabilities are 
The ergodic probabilities are $[0.079,0.921]$. These mean that value outperforms about $8 \%$ of the time. It is likely to persist for less than two months. "Growth" outperforms value $92 \%$ of the time, it is likely to persist for about 14 months if is currently outperforming. Note that the Markov nature of $S_{t}$ means that this horizon is fixed as long as growth outperformed last month.

Turning to $\mathrm{FBP}_{2}$, where $\sigma_{1} \neq \sigma_{2}$, we find quite a different model. Here, we get

$$
r_{t}=0.856 S_{t}+\left(1-S_{t}\right)(-0.608)+\left(3.005 S_{t}+1.739\left(1-S_{t}\right)\right) \varepsilon_{t}
$$

and where $\varepsilon_{t}$ is again white noise. The probabilities are

$$
\left[\begin{array}{ll}
0.832 & 0.096 \\
0.168 & 0.904
\end{array}\right]
$$

and the ergodic probabilities are $\left[\begin{array}{ll}0.365 & 0.635\end{array}\right]$. These results are interpreted that regime 1 , the value regime, is again one of higher return (about $10 \%$ pa), whilst growth is of the order of $7 \%$ pa. Value has a volatility of about $10 \%$ pa whilst growth has a volatility of about 4\%pa. States 1 and 0 have expected durations of about 6 and 10 months, and growth occurs more frequently; value outperformance is $37 \%$ versus growth underperformance at $63 \%$.

One can raise the question as to which model is more plausible; i.e., $\sigma_{1}=\sigma_{2}$ or $\sigma_{1} \neq \sigma_{2}$ ? This can be answered by hypothesis testing. Since we test only one restriction which is nested, the value of -2 times the logarithm of the likelihood ratio (LR) is asymptotically distributed as chi-squared one. We find a value of 5.02 for FBP, which is 
significant at $95 \%$ level. Therefore, we reject the restriction that the variances are equal. We conclude here that $\mathrm{FBP}_{2}$ is the preferred model.

Although we do not discuss in detail other applications, we note that the Switching Model could be applied considering the other cases. We shall not discuss them except for $\mathrm{FDE}_{1}$. This is defined as total debt per share divided by book value per share. Consulting Table 2, we note that all coefficients are significant and that regime 1 corresponds to a return of about $20 \%$ per annum, whist regime 2 corresponds to underperformance of $8 \%$ per annum. The ergodic probabilities of the two regimes are 0.396 and 0.604 respectively. The transition matrix is

$$
\left[\begin{array}{ll}
0.599 & 0.263 \\
0.401 & 0.737
\end{array}\right]
$$

If we are in a high debt to book value regime, then we expect to stay there for two periods; if we are in a low debt to book regime, we expect to stay there for about four periods. The results for this model look very promising for switching strategies.

We next investigate if the assumption of different variances is valid. We compute the LR test statistic for factor mimicking portfolios and find that the LR statistics of FRE and FGR are insignificant. Thus we cannot reject the hypothesis that variances are constant across regimes.

\subsection{One Step Ahead Expected Factor Mimicking Portfolio Returns}

This subsection examines if our Markov Switching model has any forecasting power. We compute correlations between expected factor mimicking portfolio returns and the actual returns. 
The third to sixth columns of panel A of Table 4 report average values of forecasted factor mimicking portfolio returns and correlations for within-sample forecasting cases. The average values of forecasted factor mimicking portfolio returns are similar to those of the actual numbers, see the second column of Table 4. Correlations in the fourth and sixth columns show that expected factor mimicking portfolio returns only explain around $15 \%$ of actual factor mimicking portfolio returns. Also note that there is no significant gain in the correlation values from using different variances rather than using a constant variance in the Markov Switching models.

However, the out-of-sample forecasts show quite a different story. Some of the average values of one-step ahead forecasted factor mimicking portfolio returns are quite different from the realised means of each of the FMPs, e.g., FEP and FVL1. We also observe that most of the correlations between the expected factor mimicking portfolio and the actual returns are negative. We expected the correlations to be smaller than those for the within-sample cases and in some cases these values are not different from zero. However, we did not expect the correlations to be large and negative such as -0.3956 in FRE. Why this may be so is discussed in Dacco and Satchell (1998), where the poor forecasting performance of regime based models is investigated.

In addition, Table 4 also reminds us that it is not necessarily true that the forecasting power of a model is a monotone function of the number of parameters used in the model. If it were true, the forecasts obtained from different variances model should have been better than those from the constant variance model. However, this is not true here. Similar results can be found later when we discuss trading rules. This points to the impact of estimation error generated by the inclusion of extra parameters. 
Considering the S\&P/BARRA Style index, the data cover the period from May 1975 to April 1998. Details of the Index construction are contained in Appendix 3. The S\&P / BARRA Style index consists of Growth and Value Indexes that are constructed by dividing the stocks in an index according to a single attribute: book-to-price ratio. Thus the factor mimicking portfolio obtained from the index, "Growth Index Return - Value Index Return", is similar to our FBP. However, there are some differences between FBP and the S\&P / BARRA factor mimicking portfolio (FBARRA). For the FBP, top $1 / 3$ and bottom $1 / 3$ book-to-price ratios are used, while the top $1 / 2$ and bottom 1/2 book-to-price ratios are used for the FBARRA. In addition, the S\&P / BARRA Growth and Value Indexes are value weighted portfolio, while our FBP is equally weighted. The equities used for the S\&P / BARRA Growth and Value Indexes are also not the same as our 387 equities, see Appendix 3.

Table 5 reports the statistical properties of estimates of constant variance and different variances cases. In the constant variance case, $p_{11}$ hits the boundary (zero) and the Markov Switching model is useless for dating turning points in the regime. Although transition probabilities in the difference variances case are within the boundary, none of the estimates are significant. In both cases, the transition and ergodic probabilities are close either to one or zero and Markov Switching models are not an attractive model here.

In addition to the above calculations, we tried to use the FBARRA estimates for out-of-sample forecasting. Since the data set covers a longer period than our factor mimicking portfolio series, we first replicate our factor results using the Style Index with exactly the same sample period and procedure as used in panel 1 of Table 4 . However, 
we do not obtain estimates for this estimation period due to convergence errors. We also tried to use the entire sample of the FBARRA for out-of-sample forecasting, but failed.

The explanation of the poor performance of FBARRA is based on two features of its construction. Firstly, it uses the whole universe (S\&P500); secondly it is valueweighted. Since the growth stocks are larger than the value stocks, growth is approximately the same as growth in our value index (of 357 stocks). However, value in FBARRA now contains the value in our index plus the $40 \%$ of stocks in the middle group that have no distinct characteristics.

The effect of the above is to add a lot of noise to the model. Inspection of equation (7) reveals that increasing $\sigma$ (if $\sigma_{l}=\sigma_{2}$ ) or $\sigma_{i}$ (if $\sigma_{l} \neq \sigma_{2}$ ) will swamp any switching information in the mean. The transition probabilities will be estimated as near 0 or 1, which is what happens. We conclude that FBARRA indices are poorly designed to capture regime switches. For the reason we do not repeat the analysis with Midcap 400/BARRA and Smallcap 600/BARRA Growth and Value Indexes, see Appendix 3.

\subsection{The Disappearance of Styles in the US Equity Market}

The large negative correlations between the forecasted and the realised factor mimicking portfolio returns suggest that there may be a major structural break between the last 4 years which is used as our forecasting period and the previous sampling period which is used for estimating the Markov Switching models.

To investigate a possible structural break in styles, we carry out exactly the same methods reported in subsection 4.2 but with different estimation and forecasting periods. Panel B of Table 4 reports the results for the period when we suspect that styles are not fully exploited in the US equity market; from March 1981 to December 1993. Note that 
rolling windows are used and the estimation and forecasting procedure is repeated 48 times. Therefore, the first estimation period is March 1981 to December 1989 and the first forecast period is January 1990.

Panel B of Table 4 indirectly shows possible structural breaks in styles between pre-1993 and post-1994 in two different respects. The first point is that the realised returns of factor mimicking portfolios during the period from January 1990 to December 1993 are generally much higher than those during January 1990 to December 1993, see the seventh columns of panels A and B of Table 4. During the period from January 1990 to December 1993, the number of FMPs whose absolute mean returns are larger than $0.3 \%$ a month is seven (FEP, FBP, FCP, FRE, FEG1, FVL1, FGR), while the number for the period from January 1994 to December 1997 is four (FRE, FEG1, FGR, FVG). This could be explained by the fact that some styles have been exploited and the styles do not give us excess returns.

The second point is that the negative correlations between the forecasted and the realised factor mimicking portfolio returns during the period from January 1990 to December 1993 are of smaller negative magnitude than those during the period from January 1994 to December 1997, see the ninth and eleventh columns of panels A and B of Table 4.

The two points may also be kept in mind when perusing the results of in-sample forecasts, although in this case, the sample periods overlap each other during the period from March 1981 to December 1989. Further evidence of the structural breaks of styles is reported in Tables 7 and 8, where excess returns based on the tactical style allocation during the period from January 1994 to December 1997 are much poorer than those during the period from January 1990 to December 1993, see the next section. 
In addition to these indirect results from the in-sample and out-of-sample forecasts, we need to test more directly the structural breaks of styles in the US equity market during recent years. We carried out likelihood ratio tests and found evidence of structural breaks. The likelihood ratios test results are reported in Table 6. The results reject the hypothesis that there is no structural change between sub-periods 1 and 2 . We should mention that our estimation procedure typically involves taking 36 starting values for the parameters. Rather than carry out 36 different initial value sets, we used the estimates in Tables 2 and 3 as initial value sets for sub-periods 1 and 2. This makes our test procedure conservative, since we used 36 different initial value sets to get the maximum likelihood value for the entire sample period reported in the second column of panels A and B of Table 6 . In fact, had we carried 36 initial value sets for the sub-periods 1 and 2, we might have found even more significant Chow test statistics.

\section{Tactical Style Allocation: Applications of the Markov Switching Model to Factor Mimicking Portfolios and Tactical Asset Allocation}

In subsection 4.3, we saw that out-of-sample forecasts of factor mimicking portfolio returns obtained from Markov Switching models are poor and that there is evidence of a structural break during recent years. However, this does not necessarily mean that Markov Switching models do not forecast future probabilities of states. If Markov Switching models can predict probabilities of future states, we can still use the models to obtain excess returns. We thus investigate this question by seeing if the state information can be utilised to construct profitable trading strategies.

\subsection{Trading Rules}


For our switching strategy, we predict the probability of state 1 in the next period, that is $\hat{P}_{t+1}(1)$, see Appendix 2 . Then we choose the thresholds $(\alpha, \beta)$ which will determine whether we have to hold value $\hat{P}_{t+1}(1)>\alpha$, growth if $\hat{P}_{t+1}(1)<\beta$, or a neutral position if $\beta<\hat{P}_{t+1}(1)<\alpha$. Note that $1>\alpha>\beta>0$. The state corresponding to when the probability is between $\alpha$ and $\beta$ we call the neutral state. Our interpretation is that when we do not have sufficient information to determine whether the next state is either a value or a growth state, we should be in the neutral state. The choice of $\alpha$ and $\beta$ is an empirical question. For the neutral state, we can assume that in that situation the switching strategy (a) stays at the current portfolio or (b) does not take any position.

We make the choice of $\alpha$ and $\beta$ depend upon the estimated ergodic probabilities given in tables 2 and 3. Our procedure is as follows. For the estimation period, we compute the probability that the system is in state 1 with given information, and call this $p_{t}, t=1,2, \ldots, T$. We rank these probabilities and denote the ranked probabilities by $p(t)$. If the ergodic probability of state 1 is estimated to be $\hat{\pi}_{1}$, we choose the value of $p(t)$, $p(t)^{*}$ such that the frequency that $p(t)$ is greater or equal to $p(t)^{*}$ is equal to $\hat{\pi}_{1}$. We can associate $\alpha$ with $p(t)^{*}$, this should imply that the system is in state 1 during the forecasting period with the same proportion of the time as it is in state 1 during the estimation period. In this specification, $\alpha=\beta$. If we wish $\alpha>\beta$, then we need to assure a region of non-activity.

For the case of in-sample forecasting, we have fixed $\alpha$ and $\beta$ and these are obtained using the entire sample. However, in the out-of-sample forecasting, $\alpha$ and $\beta$ are not fixed and vary through time, since $\alpha$ and $\beta$ are updated for every estimation period. 
We start with an initial investment of $\$ 1,000,000$ long in the market portfolio. If the predicted probability is greater than $\alpha$, we go long state 1 (value) and short state 0 (growth) with $\$ 1,000,000$. If the predicted probability is less than $\beta$, we go short state 1 (value) and long state 0 (growth) with $\$ 1,000,000$. If the probability is between $\alpha$ and $\beta$, we do not take a position with our hedge fund. At the end of each period, our returns are calculated and we re-examine our new forecast of probability. Then, the total value of our portfolio is invested in the market and the same amount will be invested in the hedge portfolio with the same trading rule described above. This estimation and rebalancing procedures are carried out 48 times on a monthly basis.

\subsection{Empirical Results of Tactical Style Allocation}

The results of tactical style allocation are reported in Tables 7 and 8. To investigate structural breaks in styles, we apply our trading tactics to two different periods as in the previous section: panel A's of Tables 7 and 8 reports the results for the sample period from March 1981 to December 1997 and panel B's of Tables 7 and 8 reports those from March 1981 to December 1993.

Panel A of Table 7 reports average monthly return and standard deviation of the above tactical style allocation and its annualised excess return. Even though forecasted factor mimicking portfolio returns do not explain much of the actual factor mimicking portfolio returns, we obtain positive excess returns for the case of FRE, FVL2, and FGR using the trading rule based on the forecasted probabilities. However, excess returns are marginal and considering the standard deviation of monthly returns, the results are not very exciting. Moreover, in some cases, the tactical style allocation results in large negative returns. 
The results of the tactical style allocation using different trading rules are reported in panel $\mathrm{B}$ of Table 8 . Here, $\alpha$ and $\beta$ are fixed $(0.35$ and 0.65 for constant variance and 0.4 and 0.6 for different variances). The values of $\alpha$ and $\beta$ are chosen arbitrarily. Quite surprisingly, the portfolio FRE has $7.3 \%$ and $2.9 \%$ excess return for the constant variance and different variances, while the equivalent numbers in panel $\mathrm{A}$ of Table 7 (varying $\alpha$ and $\beta$ ) are $1.7 \%$ and $0.7 \%$. This means that the results of the tactical style allocation may be very sensitive to the choice of $\alpha$ and $\beta$ in some cases. Our trading rule explained in subsection 5.1 behaves badly when one of the ergodic probabilities is close to 1 (or zero). For example, in the $36^{\text {th }}$ forecasting of the FRE, the one-step-ahead predicted probability for state 1 is 0.8 , but the trading rule assigns it state 0 . This shows that our particular trading rule can only be applied when ergodic probabilities are around 0.5 .

As explained in the previous section, the returns from a trading strategy based on different variances are poor compared with those based on the constant variance model.

When we compare the results in Tables 7 and 8, we may find some evidence that there were structural breaks in styles; few similarities can be found between the two periods. However, note that until the end of 1993, most of the annualised excess returns obtained from the trading strategies are positive, see the constant variance case in panel B of Tables 7 and 8. Some of them are very large, e.g., 9.9\% a year for FCP (panel B of Table 7). However, after 1994, the excess returns become close to zero, or large positive or negative numbers, see panel A of Tables 7 and 8 . For example, the annualised excess returns of FRE is $7.3 \%$, but that of FVG is $-4.7 \%$. 
One explanation for these changes in styles is overreaction of investors; see Bauman, Conover, and Miller (1999). They suggest that once the existence of some styles is known, investors try to exploit the styles such that some styles are fully exploited, some are under-exploited, and some are over-exploited. This may explain why some of the signs of the annualised excess returns in panel A of Tables 7 and 8 are changed from those in panel $\mathrm{B}$ of Tables 7 and 8, and why there still exist some styles which can provide significant annualised excess returns.

In this case, using styles to make an excess return is unlikely to be successful. We may recognise the existence of styles in the past, but cannot be sure if the same style can be found in the future. Some early studies on styles such as Fama and French (1992) and Sharpe (1992) show that there were some styles that could help us get excess returns. However, styles found today cannot be used for profitable investment decision making, since the styles are changing over time in an unpredictable way. Styles are useful only when they are moving in a predictable way. Once their movements become random, we can infer that the styles have disappear.

\section{Conclusions}

The conclusions of our research on regime shifts in style now follow. We estimated Markov regime models for style portfolios based on US monthly data for either the S\&P500 or the US component of the MSCI global index. Portfolio construction was found to be important. We found that the factor mimicking portfolio based on the S\&P500/BARRA Growth and Values index was obliterated a large amount of regime information. 
Our results were mixed. We found significant in-sample evidence of the existence of regimes. Out-of-sample, however, there appeared to be a lack of parameter constancy. As a consequence these models led to poor forecasts of style returns. A more interesting test is whether we could trade profitably based on the information used. However, the results were still not very good. One successful candidate appears to be FRE, which represents earnings over (lagged) book value. Other possibilities are that we have failed to identify the correct trading rule for the model or even the right model.

Another explanation to style anomaly erosion is that the overall strong performance of the US stock market has weakened any signal in the style data. This would partially explain the differences between the last four years and the previous period.

As we suggested in Section 1, what determines the distribution of style returns is a difficult question. Understanding when the returns distribution changes, as opposed to when the regimes shift from one style to another, is a question for further research. 


\section{Appendix 1: List of Definitions of Style Variables}

$$
\begin{aligned}
& \mathrm{DP}_{\mathrm{t}}=\frac{\text { dividend }(t)}{\text { share price }(t)} \\
& \mathrm{EP}_{\mathrm{t}}=\frac{\text { earnings per share }(t)}{\text { share price }(t)} \\
& \mathrm{SP}_{\mathrm{t}}=\frac{\text { net sales per share }(t)}{\text { share price }(t)} \\
& \mathrm{BP}_{\mathrm{t}}=\frac{\text { book value per share }(t)}{\text { share price }(t)} \\
& \mathrm{CP}_{\mathrm{t}}=\frac{\text { cash flow per share }(t)}{\text { share price }(t)} \\
& \mathrm{RE}_{\mathrm{t}}=\frac{\text { earnings per share }(t)}{\text { book value per share }(t-12)} \\
& \mathrm{DE}_{\mathrm{t}}=\frac{\text { total debt per share }(t)}{\text { book value per share }(t)}
\end{aligned}
$$$$
\mathrm{EG}_{t}=\log \left(\frac{\text { book value per share }(t)}{\text { book value per share }(t-24)}\right)
$$$$
\mathrm{EG} 2_{\mathrm{t}}=\log \left(\frac{\text { book value per share }(t)}{\text { book value per share }(t-12)}\right) \times 100-\log \left(\frac{\text { book value per share }(t-12)}{\text { book value per share }(t-36)}\right) \times 50
$$$$
\mathrm{SZ}_{t}=\log (\text { share price }(t) \times \text { share number }(t))
$$$$
\mathrm{VL1}_{\mathrm{t}}=\frac{\mathrm{DP}_{\mathrm{t}}+\mathrm{EP}_{\mathrm{t}}+\mathrm{CP}_{\mathrm{t}}}{3}
$$$$
\mathrm{VL} 2_{\mathrm{t}}=\frac{\mathrm{SP}_{\mathrm{t}}+\mathrm{BP}_{\mathrm{t}}}{2}
$$$$
\mathrm{GR}_{\mathrm{t}}=\frac{\mathrm{RE} \mathrm{t}_{\mathrm{t}}+\mathrm{EG} 1_{\mathrm{t}}+\mathrm{EG} 2_{\mathrm{t}}}{3}
$$$$
\mathrm{VG}_{\mathrm{t}}=\frac{\mathrm{GR}_{\mathrm{t}}+\mathrm{VL1}_{\mathrm{t}}}{2}
$$ 


\section{Appendix 2: Estimation and Forecasting Procedures}

\section{A. Estimation (see Hamilton (1989) and Hamilton (1994) for details)}

Equation (9) to be estimated in this study is

$$
r_{t}-\mu_{s_{t}}=\rho_{1}\left(r_{t-1}-\mu_{s_{t-1}}\right)+\rho_{2}\left(r_{t-2}-\mu_{s_{t-2}}\right)+\rho_{3}\left(r_{t-3}-\mu_{s_{t-3}}\right)+\rho_{4}\left(r_{t-4}-\mu_{s_{t-4}}\right)+O v_{t}
$$

Let $\theta$ be a parameter vector to be estimated, $\theta=\left(\mu_{1}, \mu_{2}, \rho_{1}, \rho_{2}, \rho_{3}, \rho_{4}, \sigma, p_{11}, p_{00}\right)$.

Let us introduce a new variable $S_{t}^{*}$ as follows;

$$
\begin{gathered}
S_{t}^{*}=1 \quad \text { if } \quad S_{t}=1, S_{t-1}=1, S_{t-2}=1, S_{t-3}=1, \text { and } S_{t-4}=1 \\
S_{t}^{*}=2 \quad \text { if } \quad S_{t}=0, S_{t-1}=1, S_{t-2}=1, S_{t-3}=1, \text { and } S_{t-4}=1 \\
\cdot \\
S_{t}^{*}=32 \quad \text { if } \quad S_{t}=0, S_{t-1}=0, S_{t-2}=0, S_{t-3}=0, \text { and } S_{t-4}=1
\end{gathered}
$$

$S_{t}^{*}$ have $32\left(=2^{5}\right)$ possible cases for equation (A1). The number 32 is based on the number of lags (4) plus one. This can be easily extended to account for different $\sigma_{i}$.

Then the optimal inference and forecast for the conditional probability vector can be obtained by iterating the following equations;

$$
\begin{aligned}
& \hat{\xi}_{t \mid t}=\frac{\hat{\xi}_{t \mid t-1} * \eta_{t}}{1^{\prime}\left(\hat{\xi}_{t \mid t-1} * \eta_{t}\right)} \\
& \hat{\xi}_{t+1 \mid t}=\widetilde{\mathbf{P}} \hat{\xi}_{t \mid t}
\end{aligned}
$$

where $\eta_{t}$ represents the $(32 \times 1)$ conditional density vector, $\widetilde{P}$ represents a $32 \times 32$ transition matrix (see, p691, Hamilton (1994) for an example of a four-state Markov transition probability matrix. In our case, we need a 32-state transition probability 
matrix.), 1 represents an $(32 \times 1)$ vector of 1 s, and $*$ denotes element-by-element multiplication.

With a starting value $\xi_{110}$ and initial value for the population parameter vector $\theta$, the values of $\hat{\xi}_{t \mid t}$ and $\hat{\xi}_{t-1 \mid t}$ can be obtained by iterating equations (A3) and (A4) for $t=1,2, \ldots, T$.

The log likelihood function $\ell(\theta)$ to be maximised against the value of $\theta$ is

$$
\ell(\theta)=\sum_{t=1}^{T} \log \left\{1^{\prime}\left(\hat{\xi}_{t \mid t-1} * \eta_{t}\right)\right\}
$$

\section{B. Forecasting (see Goodwin (1993) for details)}

The one step ahead within-sample forecasts for the Markov switching model with four lags are

$$
\begin{aligned}
E\left(r_{t+1} \mid \mathbf{R}_{t}\right) & =E\left(\mu_{s_{t+1}} \mid \mathbf{R}_{t}\right)+\sum_{i=1}^{4} \rho_{i} E\left[\left(r_{t+1-i}-\xi_{t+1-i \mid t}^{\prime} \mu\right) \mid \mathbf{R}_{t}\right] \\
& =p \xi_{t \mid t}^{\prime} \mathbf{P} \mu+\sum_{i=1}^{4} \rho_{i}\left(r_{t+1-i}-\mathrm{p}_{t+1-i \mid t} \mu\right)
\end{aligned}
$$

where $\boldsymbol{p}_{\tau \mid t}=\left(\begin{array}{c}p\left(S_{\tau}=1 \mid \boldsymbol{R}_{t}\right) \\ p\left(S_{\tau}=0 \mid \boldsymbol{R}_{t}\right)\end{array}\right)$, whose elements are sums of $\hat{\xi}_{\tau \mid t}$ for $\mathrm{S}_{\tau}=1$ and $\mathrm{S}_{\tau}=0$, respectively, $\mathbf{P}=\left[\begin{array}{cc}p_{11} & 1-p_{00} \\ 1-p_{11} & p_{00}\end{array}\right], \mu=\left(\mu_{1}, \mu_{2}\right)$ ' and other definitions of parameters are the same as in the above estimation. Note that the conditional probability vectors $p_{t+1-i \mid t}$ for $i=1,2, . ., 4$ are obtained using the nonlinear filtering method in the estimation.

The $h$ step ahead out-of-sample forecasts are 


$$
E\left(r_{t+h} \mid \mathbf{R}_{t}\right)=p_{t \mid t}^{\prime} \mathbf{P}^{h}+\sum_{i=1}^{4} \rho_{i}\left[E\left(r_{t+h-i} \mid \mathbf{R}_{t}\right)-p_{t \mid t}^{\prime} \mathbf{P}^{h-i}\right]
$$

where $p_{t \mid t}^{\prime} \mathbf{P}^{h-i} \mu=p_{t+1-i \mid t}^{\prime} \mu$ if $h-i \leq 0$. Since the first 5 observations are necessary for estimating models, we have $T-5$ within-sample forecasts where $T$ is a total number of observations.

On the other hand, in out-of-sample forecasting, the total forecasting period is set to 48 months (4 years). We use a rolling sample of the past factor mimicking portfolio returns. On day $\mathrm{t}$, the conditional expectation of one period ahead factor mimicking portfolio, $t+1$, is constructed by using the estimates which are obtained from only the past observations (i.e., the first 154 observations if the total number of observation is 202). On the next day $(t+1)$, using 154 recent observations (i.e., 154 observations from the second observation to the 155 th observation), we estimate the parameters again and get another one-step-ahead forecast. The estimation and forecasting procedures are performed 48 times using rolling windows of 154 observations.

\section{Appendix 3: Overview of S\&P / BARRA Style Indexes}

Empirical studies such as Sharpe (1991), Fama and French (1992) found that the value/growth dimension appears to explain many of the differences in returns to U.S. equity mutual funds. These findings made Standard and Poor's and BARRA begin a collaboration to produce Growth and Value subsets of S\&P's industry-leading equity indexes.

The S\&P/BARRA Growth and Value Indexes are constructed by dividing the stocks in an index according to a single attribute: book-to-price ratio. Each company in the S\&P index is assigned to either the value or growth index and the value and growth 
indexes are value-weighted. Approximately fifty percent of the combined index capitalization is in the value index and fifty percent is in the growth index.

All S\&P/BARRA Growth and Value indexes are rebalanced semi-annually on January 1 and July 1 . The values used at the time of rebalancing are the equitys position at the close of trading one month prior (i.e., November 30 and May 31). This one month lag allows enough time to invest in the indexes as of the rebalancing dates because the new constituent lists are known well in advance.

The followings are the S\&P/BARRA Growth and Value indexes;

\begin{tabular}{|c|c|c|}
\hline Index & Construction Date & History Begins \\
\hline S\&P 500/BARRA Growth and Value & May 1992 & 31 December 1974 \\
\hline Midcap 400/BARRA Growth and Value & October 1993 & 31 May 1991 \\
\hline Smallcap 600/BARRA Growth and Value & September 1996 & 31 December 1993 \\
\hline
\end{tabular}




\section{References}

Bauman, W. S. and R. E. Miller, 1997, Investor expectations and the performance of value stocks versus growth stocks, Journal of Portfolio Management 23(3), 57-68.

Bauman, W. S. and C. M. Conover, and R. E. Miller, 1999, Investor Overreaction in International Stock Markets, Journal of Portfolio Management 25(4), 102111.

Bienstock, S. and E.H. Sorenson, 1993 Segregating growth from value: its not always either/or, Salomon Brothers Discussion Paper.

Brush, J. S., 1997, Comparisons and combinations of long and long/short strategies, Financial Analysts Journal, May/June, 89-89.

Capaul, C., I. Rowley, and W. Sharpe, 1993, International value and growth stock returns, Financial Analysts Journal, 27-36.

Dacco, R., and S. Satchell, 1998, Why do regime-switching models forecast so badly?, Journal of Forecasting, forthcoming.

Erb, C. B., C. R. Harvey, and T. E. Viskanta, 1997, Demographics and International Investment, Financial Analysts Journa 53(4), 14-28.

Erb, C. B., C. R. Harvey, and T. E. Viskanta, 1996, Political Risk, Financial Risk and Economic Risk, Financial Analysts Journal 52(6), 28-46.

Ferson, W. and C. Harvey, 1997, Fundamental Determinants of International Equity Returns: A Perspective on Conditional Asset Pricing, Journal of Banking and Finance 21, 1625-1665.

Ferson, W., S. Sarkissian, and T. Simin, 1998, The alpha factor asset pricing model: a parable, (University of Washington), mimeo.

Filardo, A. J., 1994, Business-cycle phases and their transitional dynamics, Journal of Business and Economic Statistics 12(3), 299-308.

Goodwin, T. H., 1993, Business-cycle analysis with a Markov switching model, Journal of Business and Economic Statistics 11(3), 331-339.

Hamilton, J.D., 1989, A new approach to the economic analysis of nonstationary time-series and the business cycle, Econometrica 57, 357-384.

Hamilton, J.D., 1991, A quasi-Bayesian approach to estimating parameters for mixtures of normal distributions, Journal of Business and Economic Statistics 9, 27-39. 
Hamilton, J.D., 1994, Time Series Analysis, (Priceton).

Huberman, G., A. Shmuel, and R.F. Stambaugh, 1987, Mimicking portfolios and exact arbitrage pricing, Journal of Finance 42, 1-10.

Jensen, G. R., R.R. Johnson, and J.M. Mercer, 1998, The inconsistency of smallfirm and value stock premiums, Journal of Portfolio Management 24(2), 27-36.

Kim, C.J., 1993, Unobserved-component time-series models with Markov switching heteroscedasticity, Journal of Business and Economic Statistics 11(3), 341-349.

Kuberek, R.C., 1998, Using style factors to differentiate equity performance over short horizons, Journal of Portfolio Management 24(3), 33-40.

La-Porta, R., 1996, Expectations and the cross-section of stock returns, Journal of Finance 51(5), 1715-42.

Lehmann, B.N., and D.M. Modest, 1988, The empirical foundations of the arbitrage pricing theory, Journal of Financial Economics 21, 23-54.

Pagan, A.R., and G.W. Schwert, 1990, Alternative models for conditional stock volatility, Journal of Econometrics 45, 267-290.

Rozeff, M.S., and Zaman, M.A., 1998, Overreaction and insider trading: evidence from growth and value portfolios, Journal of Finance 53(2), 701-16.

Satchell, S.E., and Y. Yoon, 1996, Tactical style allocation: applications of the Markov switching model to value-growth investment and tactical asset allocation, (University of Cambridge), Discussion Paper in Accounting and Finance: AF25.

Siegel, J.J., 1995, The Nifty-fifty revisited: do growth stocks ultimately justify their price? Journal of Portfolio Management 21(4), 8-20.

Sharpe, W., 1991, Asset allocation: management style and performance measurement, Journal of Portfolio Management, 7-19.

Umstead, D.A., 1993, Value investing: a style for all seasons, Paper presented at INQUIRE Europe Conference, October. 


\section{List of other working papers:}

1999

1. Yin-Wong Cheung, Menzie Chinn and Ian Marsh, How do UK-Based Foreign Exchange Dealers Think Their Market Operates?, WP99-21

2. Soosung Hwang, John Knight and Stephen Satchell, Forecasting Volatility using LINEX Loss Functions, WP99-20

3. Soosung Hwang and Steve Satchell, Improved Testing for the Efficiency of Asset Pricing Theories in Linear Factor Models, WP99-19

4. Soosung Hwang and Stephen Satchell, The Disappearance of Style in the US Equity Market, WP99-18

5. Soosung Hwang and Stephen Satchell, Modelling Emerging Market Risk Premia Using Higher Moments, WP99-17

6. Soosung Hwang and Stephen Satchell, Market Risk and the Concept of Fundamental Volatility: Measuring Volatility Across Asset and Derivative Markets and Testing for the Impact of Derivatives Markets on Financial Markets, WP99-16

7. Soosung Hwang, The Effects of Systematic Sampling and Temporal Aggregation on Discrete Time Long Memory Processes and their Finite Sample Properties, WP99-15

8. Ronald MacDonald and Ian Marsh, Currency Spillovers and Tri-Polarity: a Simultaneous Model of the US Dollar, German Mark and Japanese Yen, WP99-14

9. Robert Hillman, Forecasting Inflation with a Non-linear Output Gap Model, WP99-13

10. Robert Hillman and Mark Salmon, From Market Micro-structure to Macro Fundamentals: is there Predictability in the Dollar-Deutsche Mark Exchange Rate?, WP99-12

11. Renzo Avesani, Giampiero Gallo and Mark Salmon, On the Evolution of Credibility and Flexible Exchange Rate Target Zones, WP99-11

12. Paul Marriott and Mark Salmon, An Introduction to Differential Geometry in Econometrics, WP99-10

13. Mark Dixon, Anthony Ledford and Paul Marriott, Finite Sample Inference for Extreme Value Distributions, WP99-09

14. Ian Marsh and David Power, A Panel-Based Investigation into the Relationship Between Stock Prices and Dividends, WP99-08

15. Ian Marsh, An Analysis of the Performance of European Foreign Exchange Forecasters, WP99-07

16. Frank Critchley, Paul Marriott and Mark Salmon, An Elementary Account of Amari's Expected Geometry, WP99-06

17. Demos Tambakis and Anne-Sophie Van Royen, Bootstrap Predictability of Daily Exchange Rates in ARMA Models, WP99-05

18. Christopher Neely and Paul Weller, Technical Analysis and Central Bank Intervention, WP9904

19. Christopher Neely and Paul Weller, Predictability in International Asset Returns: A Reexamination, WP99-03

20. Christopher Neely and Paul Weller, Intraday Technical Trading in the Foreign Exchange Market, WP99-02

21. Anthony Hall, Soosung Hwang and Stephen Satchell, Using Bayesian Variable Selection Methods to Choose Style Factors in Global Stock Return Models, WP99-01

\section{8}

1. Soosung Hwang and Stephen Satchell, Implied Volatility Forecasting: A Compaison of Different Procedures Including Fractionally Integrated Models with Applications to UK Equity Options, WP98-05

2. Roy Batchelor and David Peel, Rationality Testing under Asymmetric Loss, WP98-04

3. Roy Batchelor, Forecasting T-Bill Yields: Accuracy versus Profitability, WP98-03 
4. Adam Kurpiel and Thierry Roncalli, Option Hedging with Stochastic Volatility, WP98-02

5. Adam Kurpiel and Thierry Roncalli, Hopscotch Methods for Two State Financial Models, WP98-01 